\title{
Transcriptomic analysis of 'Suli' pear (Pyrus pyrifolia white pear group) buds during the dormancy by RNA-Seq
}

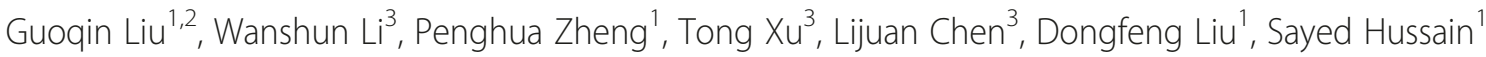 \\ and Yuanwen Teng ${ }^{1 *}$
}

\begin{abstract}
Background: Bud dormancy is a critical developmental process that allows perennial plants to survive unfavorable environmental conditions. Pear is one of the most important deciduous fruit trees in the world, but the mechanisms regulating bud dormancy in this species are unknown. Because genomic information for pear is currently unavailable, transcriptome and digital gene expression data for this species would be valuable resources to better understand the molecular and biological mechanisms regulating its bud dormancy.

Results: We performed de novo transcriptome assembly and digital gene expression (DGE) profiling analyses of 'Suli' pear (Pyrus pyrifolia white pear group) using the Illumina RNA-seq system. RNA-Seq generated approximately $100 \mathrm{M}$ high-quality reads that were assembled into 69,393 unigenes (mean length $=853 \mathrm{bp}$ ), including 14,531 clusters and 34,194 singletons. A total of 51,448 (74.1\%) unigenes were annotated using public protein databases with a cut-off E-value above $10^{-5}$. We mainly compared gene expression levels at four time-points during bud dormancy. Between Nov. 15 and Dec. 15, Dec. 15 and Jan. 15, and Jan. 15 and Feb. 15, 1,978, 1,024, and 3,468 genes were differentially expressed, respectively. Hierarchical clustering analysis arranged 190 significantly differentially-expressed genes into seven groups. Seven genes were randomly selected to confirm their expression levels using quantitative real-time PCR.
\end{abstract}

Conclusions: The new transcriptomes offer comprehensive sequence and DGE profiling data for a dynamic view of transcriptomic variation during bud dormancy in pear. These data provided a basis for future studies of metabolism during bud dormancy in non-model but economically-important perennial species.

Keywords: 'Suli' pear (Pyrus pyrifolia white pear group), Transcriptome, Bud dormancy, RNA-Seq

\section{Background}

Dormancy is a complex phase of plant development that is necessary for survival under unfavorable environmental conditions. According to Lang [1], dormancy is a temporary suspension of visible growth of any plant structures containing meristems and can be divided into five well-defined phases: paradormancy, endodormancy, ecodormancy, and the two transitional phases between para- and endodormancy and endo- and ecodormancy. Dormancy transitions are regulated by short photoperiods

\footnotetext{
* Correspondence: ywteng@zju.edu.cn

'Department of Horticulture, The State Agricultural Ministry's Key Laboratory of Horticultural Plant Growth, Development \& Quality Improvement, Zhejiang University, Hangzhou 310058, Zhejiang Province, China

Full list of author information is available at the end of the article
}

and/or chilling temperatures. In pear low temperatures have been proven to control dormancy [2]. Several excellent studies have investigated the physiological and molecular mechanisms of bud-dormancy transitions in perennial woody and herbaceous plants, including leafy spurge (Euphorbia esula Linn.) [3-5], poplar (Populus spp.) [6,7], peach (Prunus persica [L.] Batsch) [8-12], apple (Malus $\times$ domestica Borkh) [13,14], Japanese apricot (Prunus mume Siebold Zucc.) [15,16], chestnut (Castanea sativa Mill.) [17-19], grape (Vitis vinifera linn.) [20,21], raspberry (Rubus idaeus Linn.) [22], kiwifruit (Actinidia spp.) [23,24], and blackcurrant (Ribes nigrum Linn.) [25]. These results suggested that bud dormancy involves many biochemical pathways related

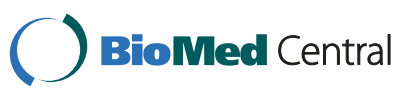

(c) 2012 Liu et al.; licensee BioMed Central Ltd. This is an Open Access article distributed under the terms of the Creative Commons Attribution License (http://creativecommons.org/licenses/by/2.0), which permits unrestricted use, distribution, and reproduction in any medium, provided the original work is properly cited. 
to photoperiod, temperature, circadian clocks, water, energy, reactive oxygen species, and hormones. Several genes involved in dormancy transition have been identified, providing useful references for studying perennial plant dormancy. However, many unresolved questions remain about how many pathways are involved, how they interact, and significant differences in dormancy transition and regulation among species, genotypes, tissues, and environments.

Pears (Pyrus spp.) are among the world's most important perennial deciduous fruit trees and have a key feature of transition from growth to dormancy during their annual growth cycles. Studies of pear dormancy have focused mainly on the physiological level, including respiration [26], carbohydrate [27,28] and protein metabolism [29], and chilling requirements [30]. To date, few studies of pear dormancy at the molecular level have been conducted. Ubi et al. (2010) isolated two dormancy-associated MADS-box (DAM) genes and studied their expression patterns during the seasonal endodormancy transition phases in Japanese pear (Pyrus pyrifolia) [31]. Although these data highlighted the potential of molecular research to understand dormancy in this crop, they were insufficient to elucidate the molecular regulation mechanism. Furthermore, with global warming, many fruit trees, including pears, growing in warm areas have suffered from inadequate winter chill and showed advanced springtime and delayed autumnal phenologies, uneven foliation and blossoming, and long blooming periods, which are unfavorable for sustainable pear production [32-37]. Therefore, understanding the molecular mechanisms of pear dormancy transitions will greatly assist programs to breed cultivars with lower chilling requirements and to develop agronomic measures to cope with insufficient winter chill.

Traditionally, researchers have studied target nucleotide sequences by cloning, sequencing and comparing with known sequences, annotating their functions, then verifying their functions using tools such as RNAi, microarrays, and genetic transformation. These methods are very useful, but characterizing a large number of genes in a single experiment is difficult, especially with respect to specific genes. In recent years, RNA-sequencing (RNA-Seq) technology based on pyro- sequencing has become the most popular and powerful tool for species that lack reference genome information. RNA-Seq is less costly, more efficient, and allows faster gene discovery and more sensitive and accurate profiles of the transcriptome than microarray analysis or other techniques [38-45]. To better understand the molecular mechanisms of bud dormancy transition in pear trees, we used RNA-Seq technology to identify and characterize the expression of a large number of genes, especially those differentially expressed during dormancy progression.
The aim of the present study was to gain an understanding of molecular mechanisms during pear bud dormancy and establish a sound foundation for future molecular studies. We sequenced cDNA libraries from lateral flower buds of 'Suli' pear (Pyrus pyrifolia white pear group) from endo to ecodormancy stages using Illumina deep-sequencing technology. Approximately $100 \mathrm{M}$ high-quality reads were obtained and assembled into 69,393 unigenes. Furthermore, four digital gene expression (DGE) libraries were constructed to compare gene expression patterns in different dormancy states using an upgraded digital gene expression system. The assembled and annotated transcriptome sequences and gene expression profiles will provide valuable resources for the identification of pear genes involved in bud dormancy.

\section{Results}

\section{Dormancy status of lateral flower buds in pears}

To identify differentially expressed genes (DEGs) during dormancy, the dormancy status of lateral flower buds in pears must be defined. Dormancy status on four collection dates was estimated using excised shoots. No bud break was observed on shoots sampled on Nov. 15 or Dec. 15 , but more than $50 \%$ of the buds had broken on Jan. 15 and Feb. 15 (Figure 1). Lateral flower buds were determined to be in the endodormant phase on Nov. 15 and Dec. 15 and in the ecodormant phase on Jan. 15 and Feb. 15.

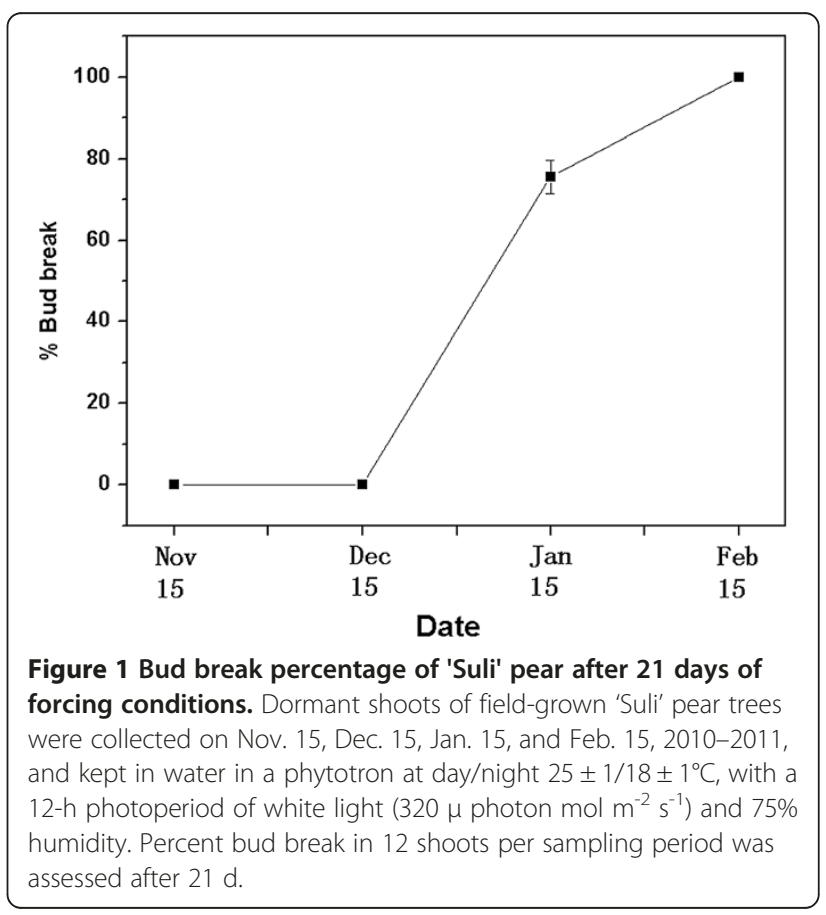




\section{Illumina sequencing and de novo assembly}

To obtain an overview of the pear bud transcriptome during dormancy, a cDNA library was generated from RNA isolated from buds pooled from Nov. 2010 to Feb. 2011, then paired-end sequenced using the Illumina platform. After cleaning and quality checks, approximately $100 \mathrm{M}$ high-quality reads were assembled into 197,357 contigs (Table 1). The mean contig size was 272 bp. Using paired-end joining and gap-filling, these contigs were further assembled into 69,393 unique sequences with a mean size of $853 \mathrm{bp}$, including 14,531 clusters and 34,194 singletons. The size distributions of these contigs and unigenes are shown in Additional file 1. To evaluate the quality of sequencing data, we randomly selected 8 unigenes and designed 8 pairs of primers (Additional file 2) for RT-PCR amplification. Each primer pair resulted in a band of the expected size; the identity of all PCR products was confirmed by Sanger sequencing.

\section{Annotation of predicted proteins}

Approximately 51,448 unique sequences were annotated based on BLASTx (cut-off E-value $10^{-5}$ ) searches of four public databases: NCBI non-redundant (nr) database, Swiss-Prot protein database, Kyoto Encyclopedia of Genes and Genomes (KEGG) database, and Gene Ontology (GO) database (Additional file 3). Among them, 47,993 unique sequences could be annotated with reference to the nr database. Based on the nr annotations, $45.3 \%$ of the annotated sequences had very strong homology (E-value $<10^{-60}$ ), and $19.6 \%$ showed strong homology $\left(10^{-60}<\right.$ E-value $\left.<10^{-30}\right)$, and an additional $35.1 \%$ showed homology $\left(10^{-30}<\mathrm{E}\right.$-value $\left.<10^{-5}\right)$, to available plant sequences (Figure $2 \mathrm{~A}$ ). The similarity distribution was comparable, with $27.0 \%$ of the sequences having similarities higher than $80 \%$, while $73.0 \%$ of the hits had similarities of $18-80 \%$ (Figure 2B). With respect to species, $31.6 \%$ of the unique sequences had top matches to sequences from Vitis vinifera, with additional hits to Ricinus communis (16.9\%), Populus

Table 1 Summary of the 'Suli' pear transcriptome during bud dormancy based on the RNA-Seq data

\begin{tabular}{ll}
\hline Total number of reads & $39,757,914$ \\
\hline Total base pairs (bp) & $3,578,212,260$ \\
\hline Average read length (bp) & 90 \\
\hline Total number of contigs & 197,357 \\
\hline Mean length of contigs (bp) & 272 \\
\hline Total number of unigenes & 69,393 \\
\hline Mean length of unigenes (bp) & 853 \\
\hline Distinct clusters & 14,531 \\
\hline Distinct sigletons & 34,194 \\
\hline Sequences with E-value $<10^{-5}$ & 51,448 \\
\hline
\end{tabular}

trichocarpa (14.8\%), Glycine max (10.3\%), and Malus $\times$ domestica (3.7\%) (Figure 2C).

\section{Functional classification}

We used GO and KEGG assignments to classify the functions of the predicted pear unigenes. Approximately 48,725 sequences could be annotated using GO, and 36,717 unigenes could be categorized into three main categories: biological process, cellular component, and molecular function. To our knowledge, the apple (Malus $\times$ domestica) genome has been completed. Among the organisms with completely-sequenced genomes, apple is most closely related to pear. Therefore, the distribution of $\mathrm{GO}$ annotations in the pear unigene data was compared with that of the apple genome (63,517 full length sequences) (ftp://ftp.jgi-psf.org/pub/JGI_data/phytozome/ v8.0/Mdomestica/annotation/Mdomestica_196_cds.fa.gz) using Blast2GO. The sequences could be categorized into $60 \mathrm{GO}$ functional groups (Figure 3). The percentages of annotated apple genes assigned to each group generally mirrored those of pear unigenes, reflecting the similar functionalities of their genomes and further highlighting that a large diversity of pear unigenes was represented by these sequences. Through sequence comparison, we observed that, although both species were highly similar, significant differences also existed between them.

There were 29,500 unigenes (approximately 42.5\%) that mapped into 128 KEGG pathways (Additional file 4). The maps with highest unigene representation were metabolic pathways (KO 01100; 7,043 unigenes, 25.1\%), followed by biosynthesis of secondary metabolites (KO 01110; 3,349 unigenes, 11.4\%), plant-pathogen interactions (KO 04626; 1,531 unigenes, $5.2 \%$ ), and plant hormone signal transduction (KO 04075; 1,357 unigenes, 4.6\%).

\section{DGE library sequencing and mapping sequences to the reference transcriptome database}

Using the RNA-seq technique, we analyzed changes in gene expression at four times during pear bud dormancy. Four DGE libraries (from buds sampled on Nov. 15, Dec. 15, Jan. 15, and Feb. 15) were sequenced to generate approximately 13-15 million clean reads per library after filtering the raw reads. The total number of mapped reads in each library ranged from 11.012.3 million, and the percentage of these reads ranged from $78.8-80.9 \%$. Among them, the number of unique match reads ranged from 7.0-7.9 million (Table 2). To confirm whether the number of detected genes increased proportionally to sequencing effort, sequence saturation analysis was performed. A trend of saturation where the number of detected genes almost ceases to increase when the number of reads reaches 5 million (Additional file 5). We evaluated the randomness of the 




Figure $\mathbf{2}$ Characteristics of homology search of pear unigenes against the $\mathrm{nr}$ database. (A) E-value distribution of the top BLAST hits for each unique sequence. (B) Similarity distribution of the top BLAST hits for each unique sequence. (C) Species distribution of the top BLAST hits for all homologous sequences.

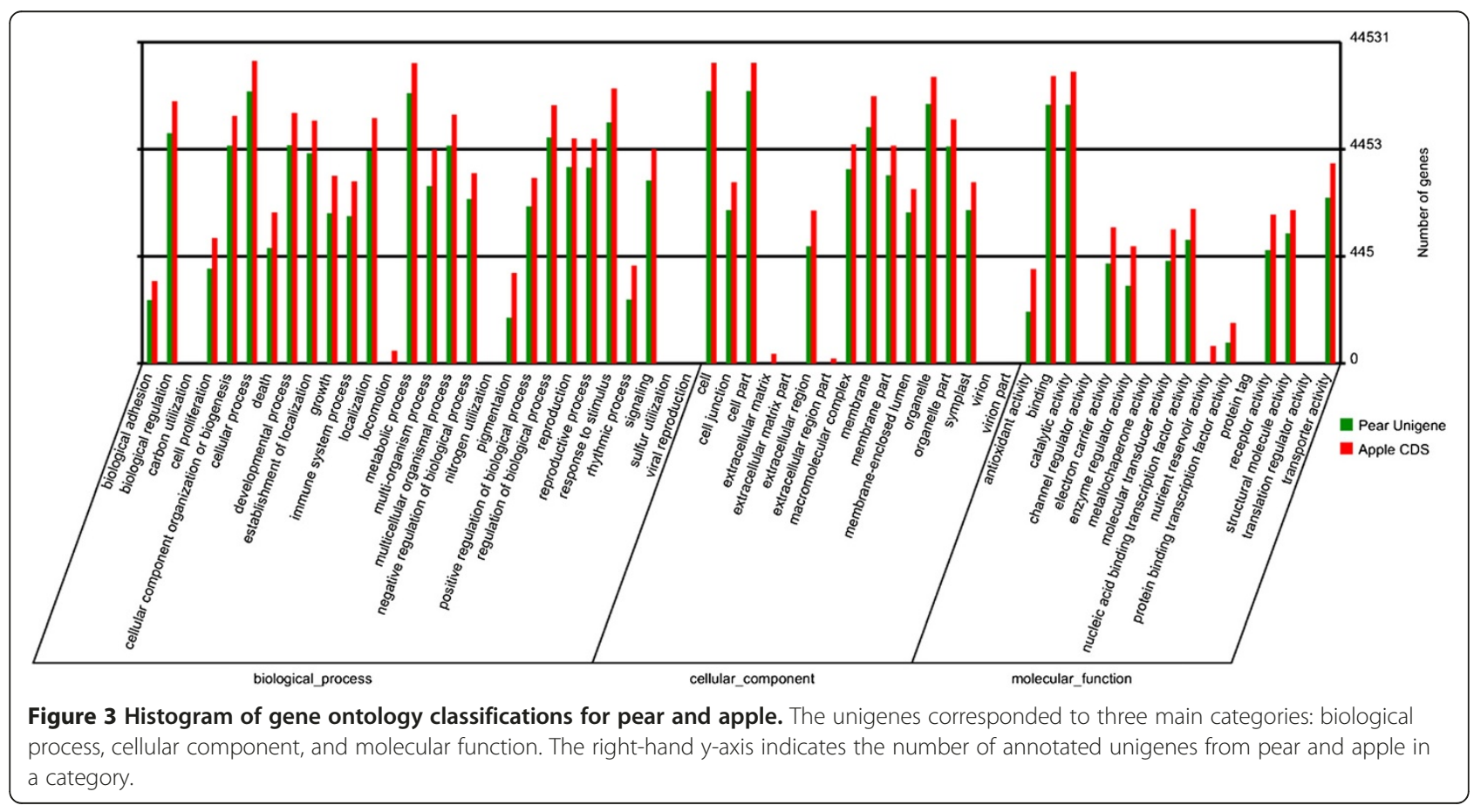


Table 2 Summary of read numbers based on the RNA-Seq data from 'Suli' pear during bud dormancy

\begin{tabular}{|c|c|c|c|c|}
\hline Summary & Nov. 15 & Dec. 15 & Jan. 15 & Feb. 15 \\
\hline Total Clean Reads & $15,156,144$ & $15,250,358$ & $14,364,828$ & $13,920,719$ \\
\hline Total Mapped Reads & $12,267,906$ & $12,336,227$ & $11,604,366$ & $10,973,976$ \\
\hline $\begin{array}{l}\text { Total Mapped Reads / } \\
\text { Total Clean Reads }\end{array}$ & $80.94 \%$ & $80.89 \%$ & $80.78 \%$ & $78.83 \%$ \\
\hline Perfect Match Reads & $9,305,310$ & $9,327,977$ & $8,832,506$ & $8,222,365$ \\
\hline $\begin{array}{l}\text { Perfect Match Reads / } \\
\text { Total Clean Reads }\end{array}$ & $61.40 \%$ & $61.17 \%$ & $61.49 \%$ & $59.07 \%$ \\
\hline$\leq 2 \mathrm{bp}$ Mismatch Reads & $2,962,596$ & $3,008,250$ & $2,771,860$ & $2,751,611$ \\
\hline $\begin{array}{l}\leq 2 \text { bp Mismatch Reads / } \\
\text { Total Clean Reads }\end{array}$ & $19.55 \%$ & $19.73 \%$ & $19.30 \%$ & $19.77 \%$ \\
\hline Unique Match Reads & $7,902,930$ & $7,977,788$ & $7,457,487$ & $7,042,745$ \\
\hline $\begin{array}{l}\text { Unique Match Reads / } \\
\text { Total Clean Reads }\end{array}$ & $52.14 \%$ & $52.31 \%$ & $51.91 \%$ & $50.59 \%$ \\
\hline $\begin{array}{l}\text { Multi-Position Match } \\
\text { Reads }\end{array}$ & $4,364,976$ & $4,358,439$ & $4,146,879$ & $3,931,231$ \\
\hline $\begin{array}{l}\text { Multi-Position Match } \\
\text { Reads / Total Clean } \\
\text { Reads }\end{array}$ & $28.80 \%$ & $28.58 \%$ & $28.87 \%$ & $28.24 \%$ \\
\hline Total-Unmapped Reads & $2,888,238$ & $2,914,131$ & $2,760,462$ & $2,946,743$ \\
\hline $\begin{array}{l}\text { Total-Unmapped Reads / } \\
\text { Total Clean Reads }\end{array}$ & $19.06 \%$ & $19.11 \%$ & $19.22 \%$ & $21.17 \%$ \\
\hline
\end{tabular}

DGE data by analyzing the distribution of reads matching the reference genes [38], because nonrandom biases for specific gene regions can directly affect subsequent bioinformatics analysis. The randomness of the data was good, with reads evenly distributed throughout the transcriptome (Additional file 6). For mRNA expression, heterogeneity and redundancy are two significant characteristics. While the majority of mRNA is expressed at low levels, a small proportion of mRNA is highly expressed. Therefore, the distribution of unique reads was used to evaluate the normality of our RNA-Seq data. As shown in Figure 4, the distribution of unique reads over different reads abundance categories showed similar patterns for all four RNA-Seq libraries. The similarity distribution had a comparable pattern with more than $43 \%$ of the sequences having a similarity of $80 \%$, while approximately $50 \%$ of the hits had a similar range (Figure 4).

\section{Changes in gene expression profiles among dormancy stages}

Differences in gene expression at four times during pear bud dormancy were examined, and DEGs were identified by pairwise comparisons of the four libraries, i.e. Nov. 15VS-Dec. 15, Nov. 15-VS-Jan. 15, Nov. 15-VS-Feb. 15, Dec. 15-VS-Jan. 15, Dec. 15-VS-Feb. 15, and Jan. 15-VS-Feb. 15 (Figure 5 \& Additional file 7, Additional file 8, Additional file 9, Additional file 10, Additional file 11, Additional file
12, respectively). Although lateral flower buds sampled on Nov. 15 and Dec. 15 were both in the endodormant stage, 1,978 genes were significantly differentially expressed between these libraries. Of these, 1,228 were down-regulated and 750 were up-regulated. Between the Dec. 15 and Jan. 15 libraries, there were 1,024 DEGs, with 443 down-regulated and 581 up-regulated. A total of 3,468 DEGs were detected between the Jan. 15 and Feb. 15 libraries, with 794 down-regulated and 2,674 up-regulated, although lateral flower buds sampled on both dates were in the endodormant-released stage. The greatest number of differentially-expressed genes occurred in the Jan. 15-VS-Feb. 15 comparison, followed by Nov. 15VS-Jan. 15, Dec. 15-VS-Feb. 15, Nov. 15-VS-Feb. 15, Nov. 15-VS-Dec. 15, and Dec. 15-VS-Jan. 15.

We analyzed the functions of the most differentiallyexpressed genes with the expression fold $\left(\log _{2}\right.$ Ratio $\left.\geq 2\right)$ and false discovery rate $\left(\mathrm{FDR} \leq 10^{-5}\right)$ as the threshold in the Nov. 15-VS-Dec. 15, Dec. 15-VS-Jan. 15, and Jan. 15VS-Feb. 15 comparisons (Additional file 13) based on NCBI annotations. In the Nov. 15-VS-Dec. 15 comparison, only two of the 20 most up-regulated genes (stachyose synthase precursor and phytosulfokines precursor) had defined functions in the NCBI database, and only one (cytochrome P450) of the twenty most down-regulated genes had defined functions. Comparing the Dec. 15 and Jan. 15 libraries, three of the twenty most up-regulated genes (i.e., WRKY transcription factor 12, transcriptional factor TINY, blue copper protein precursor) and one (non-specific lipid-transfer protein 8-like) of the twenty most down-regulated genes had defined functions. Between the Jan. 15 and Feb. 15 libraries, three of the twenty most up-regulated genes had defined functions, including genes encoding LRR receptor-like serine, phd finger protein, and arabinogalactan-protein; none of the most downregulated genes had defined functions.

\section{Functional classification of DEGs during dormancy stages}

We used GO and KEGG assignments to classify the functions of DEGs in pairwise comparisons of cDNA libraries during pear dormancy, specifically the Nov. 15VS-Dec. 15, Dec. 15-VS-Jan. 15, and Jan. 15-VS-Feb. 15 comparisons. The DEG functions were classed into three GO categories. In the cellular component category, 'plastid thylakoid, 'organelle subcompartment', 'thylakoid part', 'chloroplast thylakoid', and 'thylakoid' were significantly enriched ( $\mathrm{p}$-value $<0.05$ ) in all three pairwise comparisons. Ten other GO terms were significantly enriched only in the Dec. 15-VS-Jan. 15 and Jan. 15-VS-Feb. 15 comparisons (Figure 6A). In the molecular function category, only two GO, terms 'heme binding' and 'tetrapyrrole binding', were significantly enriched in all three pairwise comparisons, while 

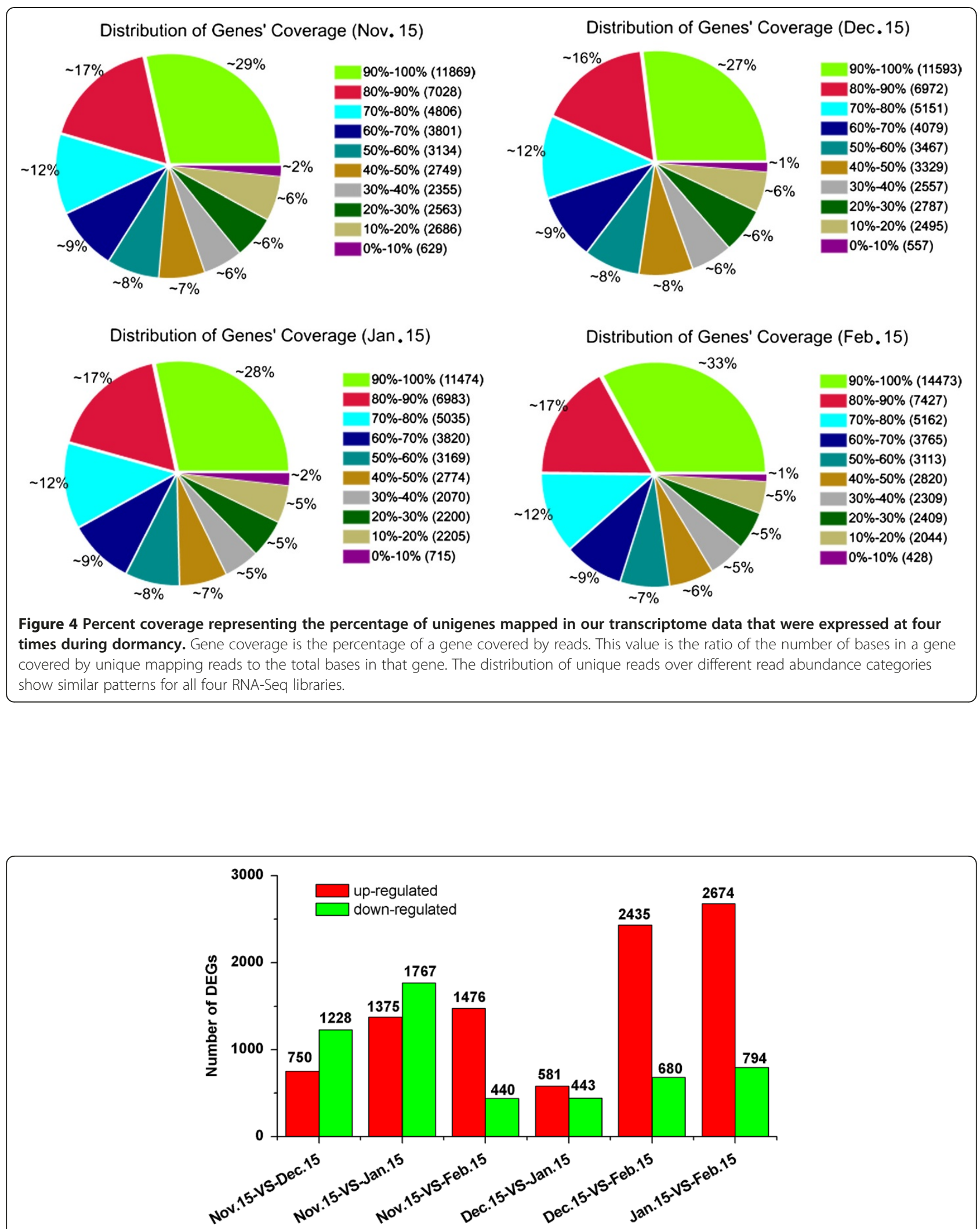

Figure 5 Changes in gene expression profiles during different dormancy stages. The numbers of up- and down-regulated genes in comparisons of the Nov. 15-VS-Dec. 15, Nov. 15-VS-Jan. 15, Nov. 15-VS-Feb. 15, Dec. 15-VS-Jan. 15, Dec. 15-VS-Feb. 15, and Jan. 15-VS-Feb. 15 libraries were summarized. DEGs: Differentially-expressed genes. 
A

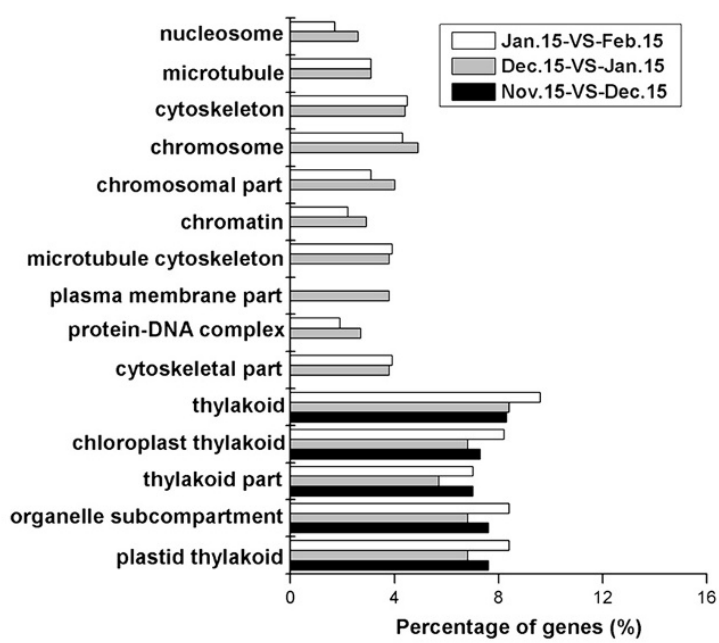

B

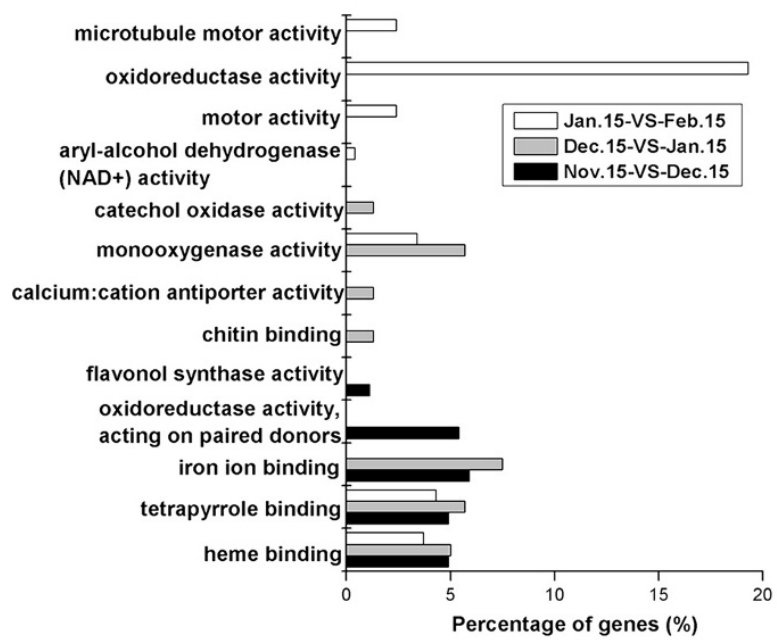

C

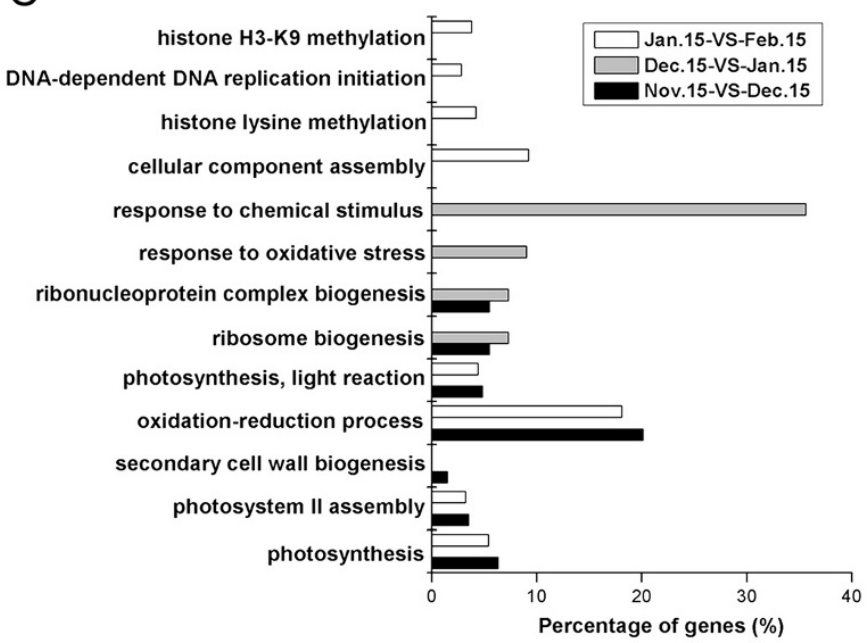

Figure 6 (See legend on next page.) 
(See figure on previous page.)

Figure 6 Functional categories of differentially-expressed genes in the Gene Ontology. GO categories that were significantly enriched (p-value < 0.05) were analyzed in pairwise comparisons (Nov. 15-VS-Dec. 15, Dec. 15-VS-Jan. 15, and Jan. 15-VS-Feb. 15). Percentages are based on the proportion of genes in each set. A: Cellular component; B: Molecular function; C: Biological process.

'monooxygenase activity' was significantly enriched in the Dec. 15-VS-Jan. 15 and Jan. 15-VS-Feb comparisons (Figure 6B). In the biological process category, no GO terms were significantly enriched in all three pairwise comparisons, but 'photosynthesis', 'photosystem II assembly', 'oxidation-reduction process', and 'photosynthesis, light reaction' were significantly enriched in the Nov. 15-VS-Dec. 15 and Jan. 15-VS-Feb. 15 comparisons, and 'ribosome biogenesis' and 'ribonucleoprotein complex biogenesis' were enriched in the Nov. 15-VS-Dec. 15 and Dec. 15-VS-Jan. 15 comparisons (Figure 6C).

In the Nov. 15-VS-Dec. 15, Dec. 15-VS-Jan. 15, and Jan. 15-VS-Feb. 15 comparisons, 666, 393, and 1,223 DEGs mapped to 104, 92, and 117 KEGG pathways, respectively. Of the 666 DEGs in the Nov. 15-VS-Dec. 15 comparison, 599 (89.9\%) mapped to 15 pathways (Additional file 14). Remarkably, specific enrichment of unigenes was observed for 15 pathways involved in metabolic processes, such as phenylpropanoid biosynthesis, ether lipid metabolism, ribosome, cutin, suberine and wax biosynthesis, stilbenoid, diarylheptanoid and gingerol biosynthesis, endocytosis, glycerophospholipid metabolism, oxidative phosphorylation, zeatin biosynthesis, flavonoid biosynthesis, starch and sucrose metabolism, fructose and mannose metabolism, other glycan degradation, and pentose and glucuronate interconversions. Comparing the Dec. 15 and Jan. 15 libraries, 343 (87.3\%) DEGs were identified in 6 pathways: ribosome, ether lipid metabolism, glycerophospholipid metabolism, endocytosis, plant-pathogen interaction, and metabolic pathways (Additional file 14). In the Jan. 15-VS-Feb. 15 comparison, 793 (64.8\%) DEGs were significantly enriched in 15 pathways (Additional file 14).

\section{Clustering analysis of DEGs during dormancy stages}

Genes with similar expression patterns are usually functionally correlated. To understand the expression patterns of 190 genes that were significantly-differentially expressed (Additional file 15) at different times in pear dormancy, cluster analyses of gene expression patterns in the Nov. 15-VS-Dec. 15, Dec. 15-VS-Jan. 15, and Jan. 15-VS-Feb. 15 comparisons were performed. These genes were arranged into seven groups (Figure 7). The largest group (Group 2) comprised the 60 (31.6\%) genes, from CL 12006 to unigene 21076, that were upregulated from Nov. 15 to Dec. 15, down-regulated between Dec. 15 and Jan. 15, then up-regulated again between Jan. 15 and Feb. 15. This group mainly included genes encoding proteins associated with ribosomes, such as $60 \mathrm{~S}$ ribosomal protein, $40 \mathrm{~S}$ ribosomal protein, translation initiation factor eIF-5A, ATP binding protein, and transaldolase.

The second largest group (Group 4) contained 56 (29.5\%) genes, from CL 12859 to CL 9922, that were down-regulated from Nov. 15 to Jan. 15 then up-regulated between Jan. 15 and Feb. 15. This group mainly included genes encoding proteins associated with photosynthesis metabolism, such as chlorophyll A/B binding protein, photosystem I reaction center subunit III, photosystem I reaction center subunit IV A, plastocyanin A, chloroplast oxygen-evolving enhancer protein 1, ribulose bisphosphate carboxylase, cytochrome P450, and magnesium-protoporphyrin IX monomethyl ester cyclase. Additionally, zinc finger protein, SPL domain class transcription factor, and basic helix-loop-helix domain-containing protein were encoded.

The third largest group (Group 5) contained 30 (15.8\%) genes, from CL 10 to unigene 27694, that were up-regulated from Nov. 15 to Jan. 15, then downregulated between Jan. 15 and Feb. 15. This group mainly included genes encoding proteins associated with oxidation-reduction reaction and resistance, such as blue copper protein, 2-oxoglutarate-dependent dioxygenase, cytochrome $\mathrm{P} 450$, heat shock protein, glycine rich protein, and dehydrin 1.

In Group 6, 17 genes (8.9\%), from CL 13025 to unigene 26541, were up-regulated between Nov. 15 and Dec. 15, but were down-regulated between Dec. 15 and Jan. 15 and between Jan. 15 and Feb. 15. This group mainly involved in genes encoding dehydrationresponsive element-binding protein, galactinol synthase 1 , and $\mathrm{GA}_{2}$-oxidase.

In Group 7, 18 genes (9.5\%), from CL 1316 to unigene 12417, were down-regulated between Nov. 15 and Dec. 15 and between Jan. 15 and Feb. 15 but were up-regulated between Dec. 15 and Jan. 15. These genes encoded proteins including fructose-bisphosphate aldolase cytoplasmic isozyme, tyrosine-protein phosphatase SIW14, glycerol-3-phosphate transporter, NAC domain class transcription factor, WRKY domain class transcription factor, and AP2 domain class transcription factor.

In Group 3, seven genes were down-regulated from Nov. 15 to Dec. 15, but were up-regulated between Dec. 15 and Feb. 15. Finally, two genes (Group 1) were up-regulated from Nov. 15 to Dec. 15, but were downregulated between Jan. 15 and Feb. 15. Of these nine genes, only 2-aminoethanethiol dioxygenase isoform 2 and transferase were definitely annotated. 


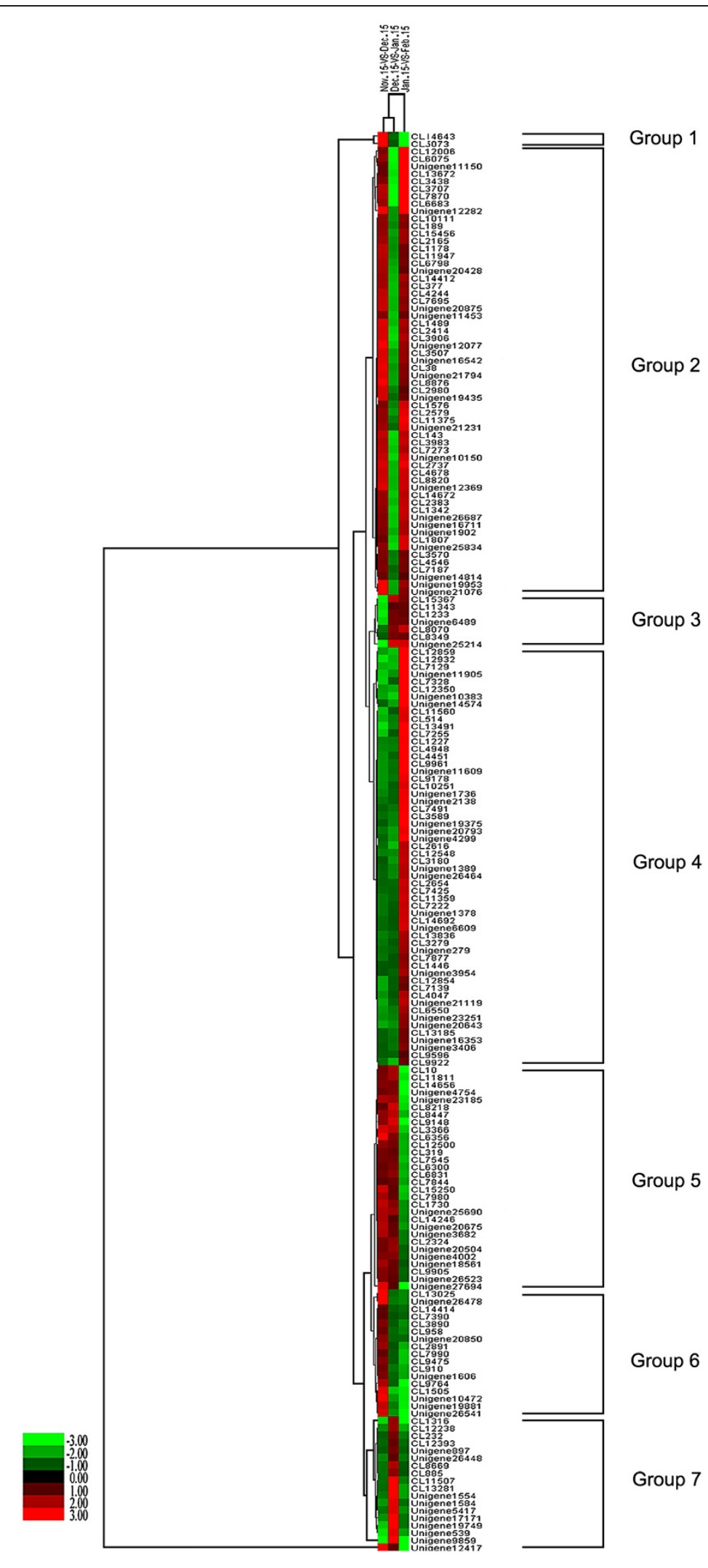

Figure 7 (See legend on next page.) 
(See figure on previous page.)

Figure 7 Hierarchical clustering analysis of differentially-expressed genes during pear dormancy. The log 2 Ratio for significantly

differentially-expressed genes were used. Each column represents a comparison of samples between dates (e.g., Nov. 15-VS-Dec. 15), and each row represents a gene. Expression differences are shown in different colors; red indicates up-regulation and green indicates down-regulation. The 190 genes were classified into seven regulation patterns.

\section{Gene expression analysis and Q-PCR validation}

The RNA sampled at four times during bud dormancy provided templates for real-time quantitative PCR (QPCR) validation. We randomly selected seven DEGs to demonstrate the RNA-seq results (Figure 8). The QPCR data for these genes were basically consistent with the RNA-seq results of the four samples. Linear regression $[(\mathrm{Q}-\mathrm{PCR}$ value $)=\alpha(\mathrm{RNA}-\mathrm{seq}$ value $)+\mathrm{b}]$ analysis showed a highly significant correlation $\left(R=0.7533^{* * * *}\right)$ which indicated good reproducibility between transcript abundance assayed by RNA-seq and the expression profile revealed by Q-PCR data (Figure 9).

\section{Phylogenetic analysis of dormancy-associated MADS-box (DAM) genes and their expression variations}

A phylogenetic tree constructed using the nucleotide sequences of two unigenes and 18 other MADS-box genes (Figure 10) revealed that CL 1161.contig2 was more closely related to PpMADS13-1 of Pyrus pyrifolia, whereas CL 1161.contig5 was more similar to PpMADS13-2 of P. pyrifolia. Additionally, the results revealed that the pear $D A M$ genes were more closely related to those of Prunus species (Prunus persica and P. mume). However, the pear $D A M$ genes formed an independent subclade.

Based on the phylogenetic analysis, we selected two unigenes (CL 1161.contig2 and CL 1161.contig5) to analyze their expression variations during dormancy. The expression levels of both genes decreased with endodormancy release in lateral flower buds (Figure 11).

\section{Discussion}

In this study, using RNA-Seq technology, a 'Suli' pear cDNA library and four DGE libraries (from samples collected on Nov. 15, Dec. 15, Jan. 15, and Feb. 15, 20102011) were constructed and used to screen DEGs during dormancy. Surprisingly, we obtained 69,393 unique sequences, and of which 51,448 could be annotated, in total 48,725 genes, including 14,531 clusters and 34,194 singletons. Until 23 May, 2012, there were only 4,339 expressed sequence tags (ESTs) and 2,837 nucleotide sequences of Pyrus plants deposited in GenBank. Several recent studies have used traditional EST analyses to study dormancy in other species. Horvath et al. (2008) and Mazzitelli et al. (2007) identified nearly 1,000 genes and 327 ESTs associated with bud dormancy in leafy spurge and raspberry, respectively, using cDNA microarrays [5,22]. Leida et al. (2010) identified nearly 400 ESTs associated with bud dormancy in peach by constructing four subtracted-cDNA libraries [46]. These ESTs participated in different metabolic pathways related to photoperiod, temperature, circadian clocks, water, energy, reactive oxygen species, and hormones $[5,22,46]$. To our knowledge, this is the first report to use RNA-Seq technique to identify large numbers of genes involved in different metabolic pathways in pear bud dormancy. Compared with traditional EST analyses, RNA-Seq was less expensive, more efficient, and allowed faster gene discovery in bud dormancy studies.

Through RNA-seq analysis, we found that the numbers and expression profiles of DEGs differed at different times during dormancy. A total of 1,978, 1,024, and 3,468 genes were differentially expressed between Nov. 15 and Dec. 15, Dec. 15 and Jan. 15, and Jan. 15 and Feb. 15, respectively. These results showed that the number of DEGs was fewer in the endodormant stage (Nov. 15 and Dec. 15) than in the ecodormant stage (Jan. 15 and Feb. 15), increased with endodormancyrelease to reach a maximum by Feb. 15. Hedley et al. (2010) reported that gene activity was lowest in the early stages of dormancy and peaked around the time of bud break in blackcurrant (Ribes nigrum L.) [25]. By analyzing KEGG pathways, we found DEGs that participated in several different pathways. Some pathways (such as starch and sucrose metabolism, circadian rhythm, and flavonoid biosynthesis) had been previously correlated to bud break in other species $[5,17,22,46]$, and some like phenylpropanoid biosynthesis, stilbenoid, diarylheptanoid and gingerol biosynthesis, zeatin biosynthesis, ether lipid metabolism, endocytosis, and glycerophospholipid metabolism were associated with bud break for the first time in this study. These data may suggest new research directions for understanding bud dormancy.

Some of the genes found in this work had been previously identified in other perennial plants. The DAM genes, widely described in perennial species such as leafy spurge [5], peach [9-12], raspberry [22], Japanese apricot [15], kiwifruit [24], and Japanese pear [31], are candidates for internal factors controlling endodormancy. In this study, we also found two $D A M$ genes, and phylogenetic analysis revealed that CL 1161.contig2 was more closely related to PpMADS13-1 of Pyrus pyrifolia, whereas CL 1161.contig5 was more similar to PpMADS13-2 of Pyrus pyrifolia. Changes in the expression of CL 1161.contig2 and CL 1161.contig5 decreased with endodormancy release in lateral flower buds were consistent with the findings of earlier work comparing PpMADS13-1 and PpMADS13-2 


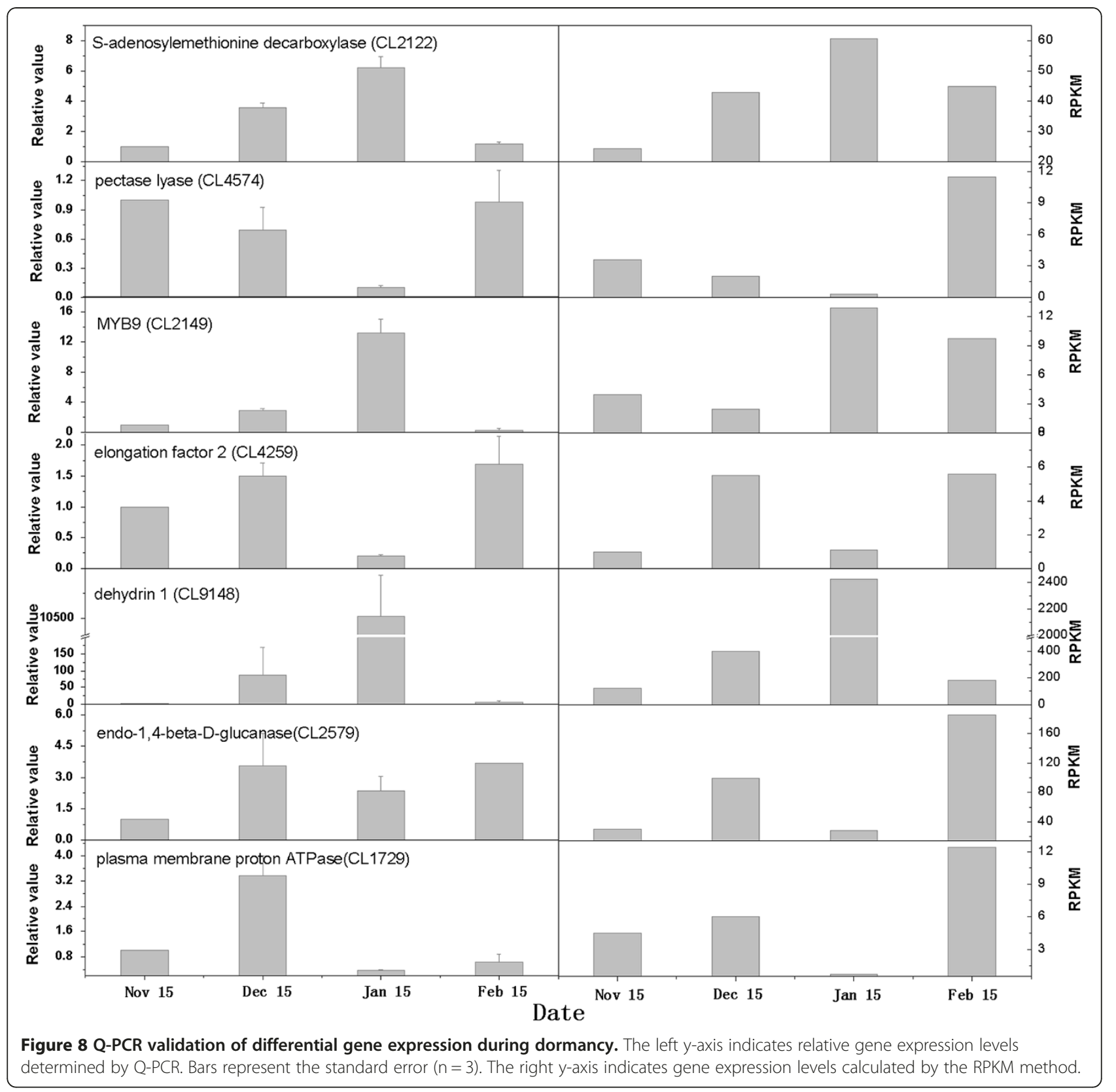

gene expression in lateral leaf buds of Japanese pear [31], $P p D A M 5$ and PpDAM6 in lateral vegetative buds and lateral flower buds of peach $[10,11]$, and all PmDAMs (PmDAM1-PmDAM6) in lateral vegetative buds of Japanese apricot [15]. Our study, along with previous studies, suggested that $D A M$ genes might play significant roles in the regulation of bud dormancy in 'Suli' pear.

The accumulation of dehydrin (DHN) is known to be associated with freezing tolerance in plants [47]. Recent studies have reported that the accumulation of DHNs in woody plants correlates with seasonal transitions in dormancy and cold acclimation stages during winter $[16,48]$, but characterizations of DHN genes expressed during dormancy are limited. Yakovlev et al. (2008) found a reduction in the transcript levels of most of the 15 DHNs that they cloned as Norway spruce neared bud-burst [48]. Garcia-Bañuelos et al. (2009) reported that transcripts of apple DHN were highly expressed in bark and bud tissues when the plant was dormant and cold hardy in midwinter, but were not expressed in early spring when cold hardiness was lost and buds were growing [49]. Recently, several studies have identified DHN genes that were activated by ABA and $\mathrm{C}$ - repeat binding factor (CBF) in response to abiotic stresses [14,50-52]. Intriguingly, in leafy spurge, ABA levels were elevated during endodormancy but dropped 


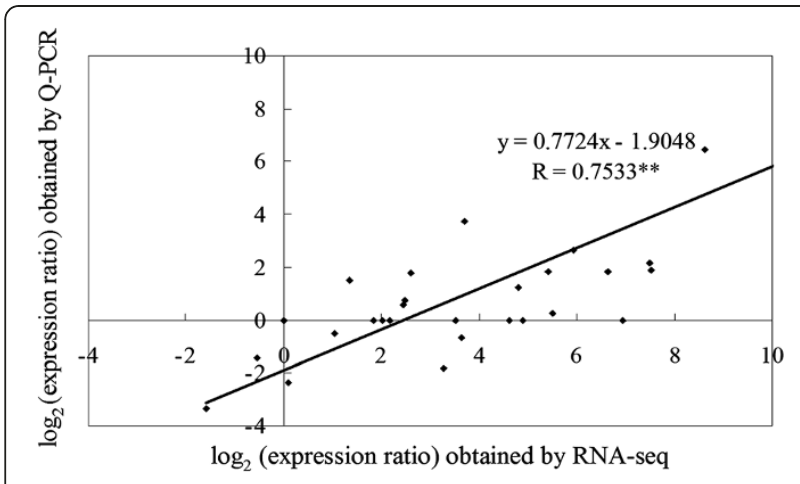

Figure 9 Coefficient analysis between gene expression ratios obtained from RNA-seq and Q-PCR data. The Q-PCR $\log _{2}$ values (expression ratios; $y$-axis) were plotted against dormancy stages $\left(x\right.$-axis). ${ }^{* *}$ indicates a significant difference at $p \leq 0.01$.

following the transition to ecodormancy [5]. Horvath et al. (2008) found that CBF genes involved in cold regulated were up-regulated during the transition from para- to endo-dormancy [5]. In the present study, one gene (CL 9148) encoding dehydrin showed significantly higher expression during the transition from endo- to eco-dormancy; thereafter, the expression level of this gene rapidly decreased, as indicated by DGE

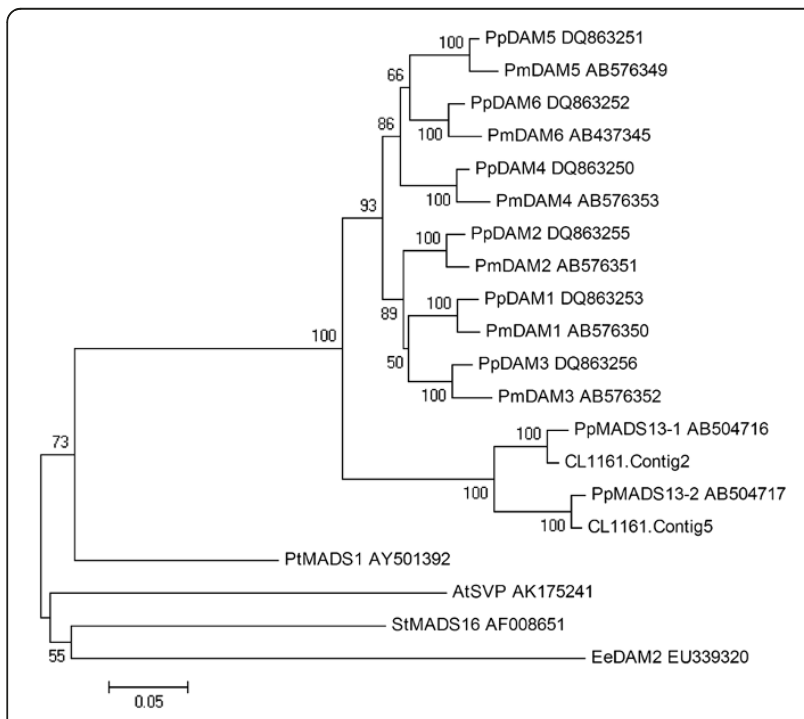

Figure 10 Phylogenetic tree of two pear unigenes and 18 other MADS-box genes. Two unigenes from 'Suli' pear (Pyrus pyrifolia white pear group; CL 1161.contig2 and CL 1161.contig5) were aligned with MADS-box genes from Prunus persica (DQ863253, DQ863255, DQ863256, DQ863250, DQ863251, and DQ863252), Prunus mume (AB576350, AB576351, AB576352, AB576353, AB576349, and AB437345), Pyrus pyrifolia (AB504716 and AB504717), Populus tomentosa (AY501392), Arabidopsis thaliana (AK175241), Solanum tuberosum (AF008651), and Euphorbia esula (EU339320). The tree was generated with MEGA 4.0.1 software using the neighbor-joining method. The numbers at each interior branch indicate bootstrap percentages from 1000 replicates. analysis and Q-PCR data. Based on previous studies, we speculated that DHN genes may act as signals and offer some protection for 'Suli' pear after the end of endodormancy, when pear often encounters unfavorable environmental conditions, such as cold. Therefore, more attention should be paid to ABA and CBF, which activate DHN genes, in future studies of transcriptional regulation related to the pear dormancy process.

Generally, sugar transport is thought to occur via $\mathrm{H}^{+}$/sugar symports that depend on a $\mathrm{pH}$ gradient generated by a plasma membrane $\mathrm{H}^{+}$-ATPase [53]. Gevaudant et al. (2001) examined expression of the four $\mathrm{H}^{+}$-ATPase genes and reported that the levels of three $\mathrm{H}^{+}$-ATPase gene mRNAs increased, whereas the level of one $\mathrm{H}^{+}$-ATPase gene decreased in vegetative buds of peach trees after dormancy release [54]. Mazzitelli et al. (2007) demonstrated that the plasma membrane $\mathrm{H}^{+}$-ATPase gene was highly expressed during the dormancy transition [22]. Our results showed that the expression of a plasma membrane $\mathrm{H}^{+}$-ATPase gene (CL 1729) was up-regulated in pear buds during the endodormant maintenance period, down-regulated during endodormancy-release, and then up-regulated again. The expression patterns of plasma membrane $\mathrm{H}^{+}$-ATPase in 'Suli' pear were different from those of peach and raspberry buds, perhaps due to species-level or tissue-level differences.

In the present study, some genes encoding galactinol synthase (CL 9475), plastocyanin A (CL 1227), chlorophyll A/ B binding protein (CL 7129, CL 514, CL 4948, CL 9178, CL 9961, CL 3279), and S-adenosylemethionine decarboxylase (CL 2122) were differentially expressed. Of these, chlorophyll $\mathrm{A} / \mathrm{B}$ binding protein and $\mathrm{S}$-adenosylemethionine decarboxylase were previously reported in other perennial plants $[46,55]$. The expression levels of these genes changed significantly during the dormancy process. Thus, these genes may play roles in the regulation of bud dormancy in 'Suli' pear.

In addition, differentially-regulated transcription factors were identified in this study, including AP2 (unigene 1554), Zn-finger (unigene 16353), NAC (CL 7187), WRKY (unigene 19749), SPL (CL 3589), and bHLH (CL 12548). Of these, AP2, Zn-finger, and NAC were previously reported in leafy spurge [5] and peach [46]. Based on DGE analysis, the expression levels of the genes encoding these transcription factors significantly changed during dormancy in 'Suli' pear.

Although the molecular mechanisms associated with dormancy transitions in pear trees remain largely unknown, the present transcriptome analysis provided valuable information that could facilitate future studies on the detailed molecular functions of genes related to pear bud dormancy. 


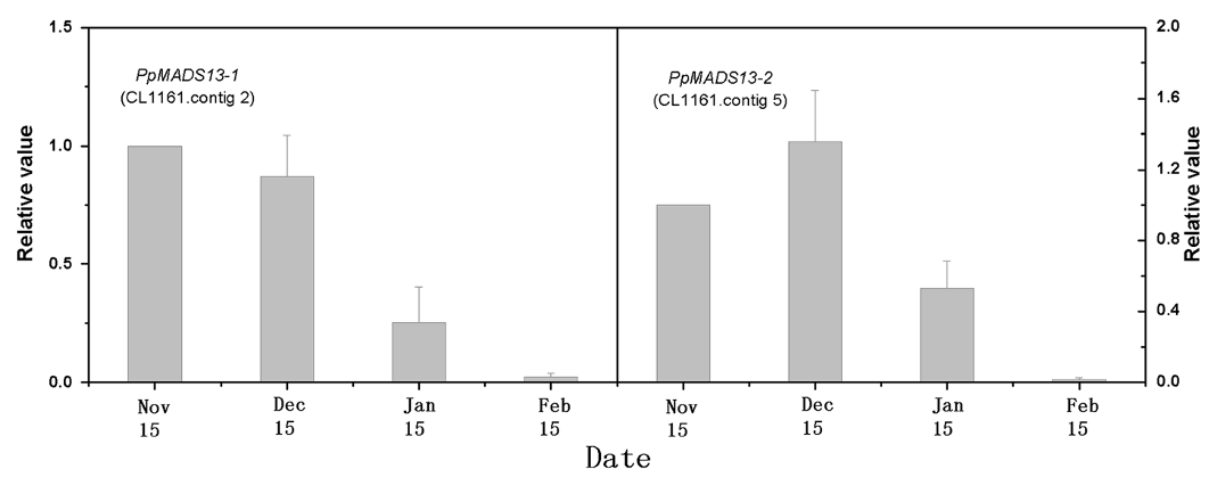

Figure 11 Relative expression levels determined by Q-PCR of CL 1161.contig2 and CL 1161.contig5 during dormancy. The left y-axis indicates the relative expression levels of $\mathrm{CL}$ 1161.contig2. The right $y$-axis indicates the relative expression levels of CL 1161.contig5. Bars represent the standard error $(n=3)$.

\section{Conclusions}

We obtained transcriptome data that provided comprehensive sequencing and DGE profiling data for a dynamic view of transcriptomic variation during the dormancy stage in pear. Physiological processes such as phenylpropanoid biosynthesis, stilbenoid, diarylheptanoid and gingerol biosynthesis, zeatin biosynthesis, ether lipid metabolism, endocytosis, glycerophospholipid metabolism, photosynthesis, phenylalanine metabolism, starch and sucrose metabolism were all differentially regulated during bud dormancy. Approximately 190 genes involved in many metabolic processes were significant differentially regulated during bud dormancy. Genes related to bud dormancy and their expression profiles at four timepoints during dormancy were analyzed further. This offered new insights into the molecular mechanisms underlying pear bud dormancy. This provided a relatively complete molecular platform for future research on the progression of pear bud dormancy. To our knowledge, this work is the first to study pear bud dormancy using RNA-Seq.

\section{Methods}

\section{Plant materials}

'Suli' pear cultivars grafted onto Pyrus betulaefolia Bunge rootstocks were obtained from the Dangshan Germplasm Resources Center (Dangshan County, Anhui Province, China). Pear trees were 10 years old and were considered to be in the adult phase. Trees used in the experiment were not pruned or chemically treated during the experimental period. All samples were collected from the same trees at each stage. The current season's growth shoots were collected on Nov. 15, Dec. 15, Jan. 15, Jan. 25and Feb. 15 from Nov. 2010 through Feb. 2011. Lateral flower bud samples were stored immediately in liquid $\mathrm{N}_{2}$ and then at $-80^{\circ} \mathrm{C}$ until RNA extraction after picking.

\section{Dormancy status of lateral flower buds}

The dormancy status of lateral flower buds at four collection dates (Nov. 15, Dec. 15, Jan. 15, and Feb. 15) was estimated by evaluating excised shoots from fieldgrown trees. To measure the percentage of bud break, 12 current season's growth shoots, with lengths of about $60 \mathrm{~cm}$ and bearing apical buds and 10-12 lateral flower buds, were collected and placed in water in $500 \mathrm{~mL}$ vials in a phytotron kept at day/night $25 \pm 1 / 18 \pm 1^{\circ} \mathrm{C}$, with a 12 -h photoperiod of white light $(320 \mu$ photon mol $\left.\mathrm{m}^{-2} \mathrm{~s}^{-1}\right)$ and $75 \%$ humidity. The water in the vials was changed and the basal ends of the shoots were cut every $2-3 \mathrm{~d}$. After $21 \mathrm{~d}$, the dormancy status was valued by percentage bud break; the beginning of bud break was defined as green leaf tips enclosing visible flowers. Lateral flower buds of shoots with bud break percentages $<50 \%$ were considered to remain in the endodormant stage.

\section{RNA extraction, library preparation and RNA-seq}

Thirty shoots (three biological replicates, with 10 shoots per replicate) with lengths of about $60 \mathrm{~cm}$ and bearing 10-12 lateral flower buds were sampled at each stage (Nov. 15, Dec. 15, Jan. 15, Jan. 25, and Feb. 15). The buds were sampled from three biological replications of each stage and produced an independent pool. Total RNA was extracted from lateral flower buds using the pine tree extraction protocol [56]. The transcriptome assembly library was pooled by mixing equal quantities of RNA of five dormancy stages. The four DGE libraries consisted of separate RNA extracts from buds of four different dormancy stages, i.e., Nov. 15, Dec. 15, Jan. 15, and Feb. 15. Each library was pooled by mixing equal quantities of RNA from three biological replications for each stage. Each pool was sequenced once technically since the RNA-seq data are highly replicable with relatively little technical variation [57]. The following protocols were performed by staff at the Beijing Genome 
Institute (BGI; Shenzhen, China). RNA integrity was confirmed with a 2100 Bioanalyzer (Agilent Technologies, Santa Clara, CA, USA). Oligo-(dT) magnetic beads were used to isolate poly-(A) mRNA from total RNA, and mRNA was fragmented in fragmentation buffer. Using these short fragments $(\approx 200 \mathrm{bp})$ as templates, random hexamer-primers were used to synthesize first-strand cDNA. Second-strand cDNA was synthesized using buffer, dNTPs, RNaseH, and DNA polymerase I. Short double-stranded cDNA fragments were purified with QiaQuick PCR extraction kit (Qiagen, Venlo, The Netherlands), resolved with EB buffer for end reparation and adding poly (A), then ligated to sequencing adapters. After purification via agarose gel electrophoresis, suitable fragments were enriched by PCR amplification before library sequencing using Illumina $\mathrm{HiSeq}^{\mathrm{TM}} 2000$ (San Diego, CA, USA).

\section{De novo assembly and function annotation}

Raw sequence data in fastq format were filtered to remove reads containing adaptors, reads with more than $5 \%$ unknown nucleotides, and low-quality reads with more than $20 \%$ bases of quality value $\leq 10$. Only clean reads were used in the following analysis. The sequences from the Illumina sequencing were deposited in the NCBI Sequence Read Archive (Accession SRX147917). First, transcriptome de novo assembly was carried out by BGI using the short-read assembly program Trinity [58] with the following parameters: min_contig_length $=100$, min_glue $=$ 2 , group_pairs_distance $=250$, path_reinforcement_distance $=75$, bfly_opts $=$ '-V 5 -edge-thr $=0.05$-stderr', min_kmer_cov $=2$. Meanwhile, all reads of approximately $100 \mathrm{M}$ (i.e. transcriptome sequencing reads and RNA-Seq reads) were mapped back to the apple genome reference (ftp://ftp.jgi-psf.org/pub/JGI_data/phytozome/ v8.0/Mdomestica/assembly/Mdomestica_196.fa.gz) to identify continuous gene regions using SOAPsplice software (Release 1.9; http://soap.genomics.org.cn/soapsplice. html). Secondly, we realigned all the transcripts onto the reference genome. When more than one transcript were placed in one gene region and they each other had an overlap less than $24 \mathrm{bp}$, we connected them into a longer transcript. A total of 31,727 transcripts assembled by Trinity were connected into 19,309 transcripts. Then the redundancy of unigenes was removed by TGICL (v.2.1) with options ' $-140-\mathrm{v} 25$ '. Finally based on gene family clustering, the unigenes were divided into two classes: clusters and singletons. The former was prefixed with 'CL' and the latter with 'unigene'. The id number of each unigene followed this prefix. In a cluster, the similarity between unigenes was more than $70 \%$.

Blastx alignment (E-value $<10^{-5}$ ) between unigenes and protein databases such as nr, Swiss-Prot, KEGG, and GO was performed, and the best-aligning results were used to determine the sequence direction of unigenes. When different databases conflicted, the results were prioritized in the order: nr, Swiss-Prot, KEGG, and GO. When a unigene did not align to any of the databases, ESTScan [59] was used to decide its sequence direction. GO annotation was analyzed by Blast2GO software (v.2.5.0). KEGG pathway annotation was performed using Blastall software against the KEGG database. The assembled sequences could be searched using the GeneID listed in Additional materials (Additional file 3).

\section{Analysis and mapping of DGE reads}

Raw sequence data in fastq format were filtered to remove reads containing adaptors, reads with more than $10 \%$ unknown nucleotides, and low-quality reads with more than $50 \%$ bases of quality value $\leq 5$. The sequences from the DGE analysis were deposited in the NCBI Sequence Read Archive under accession numbers SRX148326 (Nov. 15), SRX148327 (Dec. 15), SRX148328 (Jan. 15), and SRX148329 (Feb. 15). Clean reads were mapped to our transcriptome reference database using the short oligonucleotide analysis package SOAPaligner/ soap2 [60], allowing mismatches of no more than two bases. The unique mapped reads were used in subsequent analyses. For gene expression analysis, the number of unique-match reads was calculated and then normalized to RPKM (reads per kb per million reads) [61]. The RPKM method eliminates the influence of different gene lengths and sequencing discrepancies on the calculation of gene expression, so that the calculated gene expressions can be directly compared among samples.

\section{Evaluation of DGE libraries}

A statistical analysis of the frequency of each uniquematch read in each DGE library was performed to compare gene expression at different times in pear dormancy using the method described by Audic et al. [62]. The $P$ value was used to identify genes expressed differentially between each samples following the formula below, in which N1 and N2 represent the total numbers of unique-match reads in Samples 1 and 2, respectively, and gene A contained $\mathrm{x}$ and $\mathrm{y}$ unique-match reads mapped to Samples 1 and 2, respectively. Enriched $P$-values were calculated according to the hypergeometric test [62]:

$$
\begin{aligned}
& 2 \sum_{i=0}^{i=y} p(i \mid x)\left(\text { if } \sum_{i=0}^{i=y} p(i \mid x) \leq 0.5\right) \text { or } \\
& 2 \times\left(1-\sum_{i=0}^{i=y} p(i \mid x)\right)\left(\text { if } \sum_{i=0}^{i=y} p(i \mid x)>0.5\right)
\end{aligned}
$$




$$
p(y \mid x)=\left(\frac{N_{2}}{N_{1}}\right)^{y} \frac{(x+y) !}{x ! y !\left(1+\frac{N_{2}}{N_{1}}\right)^{(x+y+1)}}
$$

The false discovery rate (FDR) was used to determine the $P$-value threshold in multiple testing [63]. Briefly, assuming that $\mathrm{R}$ differentially expressed genes had been selected, $\mathrm{S}$ genes of those were really shown differential expression, whereas the other $\mathrm{V}$ genes actually indicated no difference which were false positive. If the error ratio $(\mathrm{Q}=\mathrm{V} / \mathrm{R})$ was required to remain below a specified cutoff (0.01), the FDR value should not exceed 0.01 . FDR-values were calculated according to the Benjamini and Hochberg algorithm [63]:

$$
F D R=E(Q)=E\{V /(V+S)\}=E(V / R)
$$

We used FDR $\leq 0.001$, the absolute value of $\log _{2}$ Ratio $\geq$ 1 , and the RPKM value of each gene for either sample over 10 as the thresholds to judge the significance of gene expression differences, where $\log _{2}$ Ratio indicates the degree of differential expression between two samples and was the ratio of RPKM values for the treatment and control samples. This analysis found genes with significantly differential expression among samples prior to GO function and KEGG pathway analyses.

\section{Clustering of gene expression profiles}

Hierarchical cluster analysis of 190 gene expression patterns was performed with cluster [64] and Java Treeview [65] software. The $\log _{2}$ Ratio for each gene was used for the hierarchical clustering analysis.

\section{Phylogenetic analysis}

A phylogenetic tree was constructed based on the nucleotide sequences of two unigenes and 18 additional $D A M$ genes. The tree was generated with MEGA (v. 4.0.1) [66] software, using the neighbor-joining method.

\section{Real-time quantitative RT-PCR analysis}

Total RNA used for Q-PCR analysis was extracted from lateral flower buds of four different dormancy stages, i.e., Nov. 15, Dec. 15, Jan. 15, and Feb. 15, using three biological replicates of about 300 buds. Total RNA was extracted as described above, genomic DNA was removed with DNase I, and total RNA concentration was measured. First-strand cDNA was synthesized from $4 \mu \mathrm{g}$ of DNA-free RNA using the Revert Aid ${ }^{\mathrm{TM}}$ First Strand cDNA Synthesis Kit (Fermentas, Glen Burnie, MD, USA) according to the manufacturer's instructions. The cDNA was used as the template for Q-PCR. Primer sequences (designed using primer 3, http://frodo.wi.mit.edu/cgi-bin/ primer3/primer3_www.cgi) are listed in Additional file 16. The Q-PCR mixture $(20 \mu \mathrm{l}$ total volume) contained $10 \mu \mathrm{l}$ of SYBR Premix ExTaq ${ }^{\mathrm{TM}}$ (Takara, Kyoto, Japan), 0.4 $\mu \mathrm{l}$ of each primer $(10 \mu \mathrm{M}), 2 \mu \mathrm{l}$ of $\mathrm{cDNA}$, and $7.2 \mu \mathrm{l}$ of RNasefree water. The reactions were performed on a LightCycler 1.5 instrument (Roche, Basel, Switzerland) according to the manufacturer's instructions. The two-step Q-PCR program began with 30 seconds at $95^{\circ} \mathrm{C}$, followed by 40 cycles of $95^{\circ} \mathrm{C}$ for 5 seconds and $60^{\circ} \mathrm{C}$ for 20 seconds. Template-less controls for each primer pair were included in each run. The specificity of Q-PCR primers was confirmed by melting curve and sequencing of Q-PCR products. Expression was calculated as $2^{-\Delta} \Delta \mathrm{Ct}$ and normalized to that of the actin gene (PpActin, JN684184) [67], and data were managed with the Data Processing System (DPS, v. 7.05, Zhejiang University, Hangzhou, China).

\section{Additional files}

Additional file 1: Overview of 'Suli' pear (Pyrus pyrifolia white pear group) transcriptome sequencing and assembly. (A) Size distribution of Illumina sequencing contigs. (B) Size distribution of unigenes after paired-end and gap filling.

Additional file 2: Primers used in RT-PCR to evaluate the quality of unigene sequencing data.

Additional file 3: Top BLAST hits from the four public database (nr, SwissProt, KEGG, and GO).

Additional file 4: The 29,500 unigenes assigned to 128 KEGG pathways.

Additional file 5: Sequencing saturation analysis of the four libraries. All libraries approached saturation as the number of reads approached 5 million, as indicated by the decline in the number of new genes detected.

Additional file 6: Distribution of reads on reference genes. All libraries showed good levels of randomness, with the number of reads evenly distributed throughout the transcriptomes.

Additional file 7: Differentially-expressed genes between the Nov. 15 and Dec. 15 libraries. Genelength: length of all exon in gene. Expression: unique reads of aligned reads. RPKM: Reads Per Kb per Million reads. $\log _{2}$ Ratio: $\log _{2}$ (Dec. 15-RPKM/Nov. 15-RPKM). Up-DownRegulation (Dec. 15/Nov. 15): Dec. 15 is a up/down regulation relative to Nov. 15. P-value: pvalue for hypothesis testing. FDR: false discovery rate. We used FDR $\leq 0.001$ and the absolute value of $\log _{2}$ Ratio $\geq 1$ as the threshold to judge the significance of gene expression difference.

Additional file 8: Differentially-expressed genes between the Nov. 15 and Jan. 15 libraries. Genelength: length of all exon in gene. Expression: unique reads of aligned reads. RPKM: Reads Per Kb per Million reads. $\log _{2}$ Ratio: $\log _{2}$ (Jan. 15-RPKM/Nov. 15-RPKM). Up-Down-Regulation (Jan. 15/Nov. 15): Jan. 15 is a up/down regulation relative to Nov. 15.

P-value: pvalue for hypothesis testing. FDR: false discovery rate. We used $F D R \leq 0.001$ and the absolute value of $\log _{2}$ Ratio $\geq 1$ as the threshold to judge the significance of gene expression difference.

Additional file 9: Differentially-expressed genes between the Nov. 15 and Feb. 15 libraries. Genelength: length of all exon in gene. Expression: unique reads of aligned reads. RPKM: Reads Per Kb per Million reads. $\log _{2}$ Ratio: $\log _{2}$ (Feb. 15-RPKM/Nov. 15-RPKM). Up-Down-Regulation (Feb. 15/Nov. 15): Feb. 15 is a up/down regulation relative to Nov. 15. P-value: pvalue for hypothesis testing. FDR: false discovery rate. We used FDR $\leq 0.001$ and the absolute value of $\log _{2}$ Ratio $\geq 1$ as the threshold to judge the significance of gene expression difference.

Additional file 10: Differentially-expressed genes between the Dec. 15 and Jan. 15 libraries. Genelength: length of all exon in gene. Expression: unique reads of aligned reads. RPKM: Reads Per Kb per Million 
reads. $\log _{2}$ Ratio: $\log _{2}$ (Jan. 15-RPKM/Dec. 15-RPKM). Up-Down-Regulation (Jan. 15/Dec. 15): Jan. 15 is a up/down regulation relative to Dec. 15 . P-value: pvalue for hypothesis testing. FDR: false discovery rate. We used FDR $\leq 0.001$ and the absolute value of $\log _{2}$ Ratio $\geq 1$ as the threshold to judge the significance of gene expression difference.

Additional file 11: Differentially-expressed genes between the Dec. 15 and Feb. 15 libraries. Genelength: length of all exon in gene. Expression: unique reads of aligned reads. RPKM: Reads Per Kb per Million reads. $\log _{2}$ Ratio: $\log _{2}$ (Feb. 15-RPKM/Dec. 15-RPKM). Up-Down-Regulation (Feb. 15/Dec. 15): Feb. 15 is a up/down regulation relative to Dec. 15. P-value: pvalue for hypothesis testing. FDR: false discovery rate. We used FDR $\leq 0.001$ and the absolute value of $\log _{2}$ Ratio $\geq 1$ as the threshold to judge the significance of gene expression difference.

Additional file 12: Differentially-expressed genes between the Jan. 15 and Feb. 15 libraries. Genelength: length of all exon in gene. Expression: unique reads of aligned reads. RPKM: Reads Per Kb per Million reads. $\log _{2}$ Ratio: $\log _{2}$ (Feb. 15-RPKM/Jan. 15-RPKM). Up-Down-Regulation (Feb. 15/Jan. 15): Feb. 15 is a up/down regulation relative to Jan. 15. P-value: pvalue for hypothesis testing. FDR: false discovery rate. We used FDR $\leq 0.001$ and the absolute value of $\log _{2}$ Ratio $\geq 1$ as the threshold to judge the significance of gene expression difference.

Additional file 13: The top 20 most up-regulated and downregulated DEGs between samples (Nov. 15-VS-Dec. 15, Dec. 15-VSJan. 15 and Jan. 15-VS-Feb. 15). RPKM: Reads Per Kb per Million reads. DEGs: Differentially-expressed genes with the expression fold $\left(\log _{2}\right.$ Ratio $\left.\geq 2\right)$ and false discovery rate $\left(F D R \leq 10^{-5}\right)$ as the threshold.

Additional file 14: KEGG pathways significantly enriched during dormancy. KEGG pathways significantly enriched were defined as pathways with Q-value $\leq 0.05$.

Additional file 15: 190 genes differentially expressed during dormancy. In total, 190 genes were found that were significantly differentially-expressed genes between Nov. 15 and Dec. 15, between Dec. 15 and Jan. 15, and between Jan. 15 and Feb. 15. 190 genes with annotations and their expression fold between Nov. 15 and Dec. 15, between Dec. 15 and Jan. 15, and between Jan. 15 and Feb. 15.

Additional file 16: Primers used in Q-PCR to validate differential expression during pear dormancy.

\section{Abbreviations}

BGI: Beijing Genome Institute; BLAST: Basic local alignment search tool; DAM: Dormancy-associated MADS-box; DEG: Differentially-expressed gene; DGE: Digital gene expression; DHN: Dehydrin; DPS: Data processing system; EST: Expressed sequence tag; FDR: False discovery rate; KEGG: The Kyoto encyclopedia of genes and genomes database; KO: KEGG Orthology ids; MEGA: Molecular evolutionary genetics analysis; nr: NCBI non-redundant database; Q-PCR: Real-time quantitative PCR; RNA-Seq: RNA-sequencing: RPKM: Reads per kb per million reads; SOAP: Short oligonucleotide analysis package.

\section{Competing interests}

The authors declare that they have no competing interests.

\section{Authors' contributions}

GQL carried out the experiment, analyzed the data and drafted the manuscript. WSL carried out bioinformatics analysis. PHZ carried out the experiment and participated in data analysis. TX participated in data analysis. LC participated in data analysis. DFL carried out the experiment. HS helped to draft the manuscript. YWT initiated and supervised the study. All authors read and approved the final manuscript.

\section{Acknowledgements and funding}

This research was financed by the earmarked fund for Modern Agro-industry Technology Research System (nycytx-29).

We acknowledge the Dangshan Germplasm Resources Center for providing materials.

\section{Author details}

'Department of Horticulture, The State Agricultural Ministry's Key Laboratory of Horticultural Plant Growth, Development \& Quality Improvement, Zhejiang University, Hangzhou 310058, Zhejiang Province, China. ${ }^{2}$ College of Agriculture, Guizhou University, Guiyang 550025, Guizhou Province, China. ${ }^{3}$ BGl-tech, Shenzhen 518083, Guangdong Province, China.

Received: 20 June 2012 Accepted: 7 December 2012

Published: 12 December 2012

\section{References}

1. Lang G, Early J, Martin G, Darnell R: Endo-, para-, and ecodormancy: physiological terminology and classification for dormancy research. Hortscience 1987, 22:371-377.

2. Heide O, Prestrud A: Low temperature, but not photoperiod, controls growth cessation and dormancy induction and release in apple and pear. Tree Physiol 2005, 25(1):109-114.

3. Chao WS, Serpe MD, Anderson JV, Gesch RW, Horvath DP: Sugars, hormones, and environment affect the dormancy status in underground adventitious buds of leafy spurge (Euphorbia esula). Weed Science 2006, 54(1):59-68

4. Horvath DP, Chao WS, Anderson JV: Molecular analysis of signals controlling dormancy and growth in underground adventitious buds of leafy spurge. Plant Physiol 2002, 128(4):1439-1446.

5. Horvath DP, Chao WS, Suttle JC, Thimmapuram J, Anderson JV: Transcriptome analysis identifies novel responses and potential regulatory genes involved in seasonal dormancy transitions of leafy spurge (Euphorbia esula L.). BMC Genomics 2008, 9:536.

6. Bohlenius H, Huang T, Charbonnel-Campaa L, Brunner AM, Jansson S: CO/FT regulatory module controls timing of flowering and seasonal growth cessation in trees. Science 2006, 312(5776):1040.

7. Ruttink T, Arend M, Morreel K, Storme V, Rombauts S, Fromm J, Bhalerao RP, Boerjan W, Rohde A: A molecular timetable for apical bud formation and dormancy induction in poplar. Plant Cell 2007, 19(8):2370-2390.

8. Yooyongwech S, Sugaya S, Sekozawa Y, Gemma H: Differential adaptation of high-and low-chill dormant peaches in winter through aquaporin gene expression and soluble sugar content. Plant Cell Rep 2009, 28(11):1709-1715.

9. Leida C, Conesa A, Llácer G, Badenes ML, Ríos G: Histone modifications and expression of DAM6 gene in peach are modulated during bud dormancy release in a cultivar-dependent manner. New Phytol 2012 193(1):67-80.

10. Yamane H, Ooka T, Jotatsu H, Sasaki R, Tao R: Expression analysis of PpDAM5 and PpDAM6 during flower bud development in peach (Prunus persica). Sci Hortic 2011, 129(4):844-848.

11. Yamane H, Ooka T, Jotatsu H, Hosaka Y, Sasaki R: Expressional regulation of PpDAM5 and PpDAM6, peach (Prunus persica) dormancy-associated MADS-box genes, by low temperature and dormancy-breaking reagent treatment. J Exp Bot 2011, 62(10):3481-3488

12. Bielenberg DG, Wang Y, Li ZG, Zhebentyayeva T, Fan SH, Reighard GL, Scorza R, Abbott AG: Sequencing and annotation of the evergrowing locus in peach [Prunus persica (L.) Batsch] reveals a cluster of six MADSbox transcription factors as candidate genes for regulation of terminal bud formation. Tree Genetics \& Genomes 2008, 4(3):495-507.

13. Brunel N, Leduc N, Poupard P, Simoneau P, Mauget JC, Viemont JD: KNAP2, a class I KN1-like gene is a negative marker of bud growth potential in apple trees (Malus domestica [L.] Borkh.). J Exp Bot 2002, 53(378):2143-2149.

14. Wisniewski M, Norelli J, Bassett C, Artlip T, Macarisin D: Ectopic expression of a novel peach (Prunus persica) CBF transcription factor in apple (Malus $\times$ domestica) results in short-day induced dormancy and increased cold hardiness. Planta 2011, 233(5):971-983.

15. Sasaki R, Yamane H, Ooka T, Jotatsu H, Kitamura Y, Akagi T, Tao R: Functional and Expressional Analyses of PmDAM Genes Associated with Endodormancy in Japanese Apricot. Plant Physiol 2011, 157(1):485-497.

16. Yamane $H$, Kashiwa $Y$, Kakehi E, Yonemori K, Mori H, Hayashi K, Iwamoto K, Tao R, Kataoka I: Differential expression of dehydrin in flower buds of two Japanese apricot cultivars requiring different chilling requirements for bud break. Tree Physiol 2006, 26(12):1559-1563. 
17. Ramos A, Pérez-Solís E, Ibáñez C, Casado R, Collada C, Gómez L, Aragoncillo C, Allona I: Winter disruption of the circadian clock in chestnut. Proc Nat Acad Sci U S A 2005, 102(12):7037

18. Santamaria ME, Rodriguez R, Canal MJ, Toorop PE: Transcriptome analysis of chestnut (Castanea sativa) tree buds suggests a putative role for epigenetic control of bud dormancy. Ann Bot 2011, 108:485-498.

19. Ibañez C, Ramos A, Acebo P, Contreras A, Casado R, Allona I, Aragoncillo C Overall alteration of circadian clock gene expression in the chestnut cold response. PLoS One 2008, 3(10):e3567.

20. Pacey-Miller T, Scott K, Ablett E, Tingey S, Ching A, Henry R: Genes associated with the end of dormancy in grapes. Funct Integr Genomics 2003, 3(4):144-152

21. Ophir R, Pang X, Halaly T, Venkateswari J, Lavee S, Galbraith D, Or E: Geneexpression profiling of grape bud response to two alternative dormancy-release stimuli expose possible links between impaired mitochondrial activity, hypoxia, ethylene-ABA interplay and cell enlargement. Plant Mol Biol 2009, 71(4):403-423.

22. Mazzitelli L, Hancock RD, Haupt S, Walker PG, Pont SDA, McNicol J, Cardle L, Morris J, Viola R, Brennan R: Co-ordinated gene expression during phases of dormancy release in raspberry (Rubus idaeus L.) buds. J Exp Bot 2007 58(5):1035-1045.

23. Richardson AC, Walton EF, Meekings JS, Boldingh HL: Carbohydrate changes in kiwifruit buds during the onset and release from dormancy. Sci Hortic 2010, 124(4):463-468.

24. Wu R-M, Walton EF, Richardson AC, Wood M, Hellens RP, Varkonyi-Gasic E: Conservation and divergence of four kiwifruit SVP-like MADS-box genes suggest distinct roles in kiwifruit bud dormancy and flowering. J Exp Bot 2012, 63(2):797-807.

25. Hedley PE, Russell JR, Jorgensen L, Gordon S, Morris JA, Hackett CA, Cardle $L$, Brennan $R$ : Candidate genes associated with bud dormancy release in blackcurrant (Ribes nigrum L.). BMC Plant Biol 2010, 10:202.

26. Bi L, Zhang Y, Poudyal B: Effects of growth regulators on the respiration metabolism of pear buds during dormant period. Frontiers of Agriculture in China 2011, 5(1):45-50.

27. Zimmerma RH, Faust M: Pear Bud Metabolism - Seasonal Changes in Glucose Utilization. Plant Physiol 1969, 44(9):1273-1276.

28. Marafon AC, Citadin I, Amarante L, Herter FG, Hawerroth FJ: Chilling privation during dormancy period and carbohydrate mobilization in Japanese pear trees. Scientia Agricola 2011, 68(4):462-468.

29. Tamura F, Tanabe K, Itai A, Tanaka H: Protein changes in the flower buds of Japanese pear during breaking of dormancy by chilling or hightemperature treatment. J Am Soc Hortic Sci 1998, 123(4):532-536.

30. Kretzschmar A, Brighenti L, Rufato L, Pelizza T, Silveira F, Miquelutti D, Faoro I: Chilling Requirement for Dormancy Bud Break in European Pear. Acta Hortic 2011, 909:85-87.

31. Ubi BE, Sakamoto D, Ban Y, Shimada T, Ito A, Nakajima I, Takemura Y, Tamura F, Saito T, Moriguchi T: Molecular cloning of dormancy-associated MADS-box gene homologs and their characterization during seasonal endodormancy transitional phases of Japanese pear. J Am Soc Hortic SCi 2010, 135(2):174-182.

32. Cannell M, Smith R: Climatic warming, spring budburst and forest damage on trees. J App/ Ecol 1986, 177-191.

33. Young E: Timing of high temperature influences chilling negation in dormant apple trees. J Am Soc Hortic Sci 1992, 117(2):271-273.

34. Luedeling E, Zhang M, Girvetz EH: Climatic changes lead to declining winter chill for fruit and nut trees in California during 1950-2099. PLoS One 2009, 4(7):e6166.

35. Anderson J, Horvath D, Chao W, Foley M: Bud Dormancy in Perennial Plants: A Mechanism for Survival. In Dormancy and Resistance in Harsh Environments. vol. 21st edition. Edited by Lubzens E, Cerda J, Clark M. Heidelberg: Springer Berlin; 2010:69-90.

36. Campoy J, Ruiz D, Egea J: Dormancy in temperate fruit trees in a global warming context: A review. Sci Hortic 2011, 130(2):357-372.

37. Luedeling E, Girvetz EH, Semenov MA, Brown PH: Climate change affects winter chill for temperate fruit and nut trees. PLoS One 2011, 6(5):e20155

38. Wang Z, Gerstein M, Snyder M: RNA-Seq: a revolutionary tool for transcriptomics. Nat Rev Genet 2009, 10(1):57-63.

39. Feng $C$, Chen $M, X u C J$, Bai L, Yin XR, Li X, Allan AC, Ferguson IB, Chen KS: Transcriptomic analysis of Chinese bayberry (Myrica rubra) fruit development and ripening using RNA-Seq. BMC Genomics 2012, 13:19.
40. Xue J, Bao YY, Li B, Cheng YB, Peng ZY: Transcriptome analysis of the brown planthopper Nilaparvata lugens. PLoS One 2010, 5(12):e14233.

41. Martinez-Gomez P, Crisosto $\mathrm{CH}$, Bonghi C, Rubio M: New approaches to Prunus transcriptome analysis. Genetica 2011, 139(6):755-769.

42. Tang Q, Ma XJ, Mo CM, Wilson IW, Song C, Zhao H, Yang YF, Fu W, Qiu DY An efficient approach to finding Siraitia grosvenorii triterpene biosynthetic genes by RNA-seq and digital gene expression analysis. BMC Genomics 2011, 12:343.

43. Yu K, Xu Q, Da X, Guo F, Ding Y, Deng X: Transcriptome changes during fruit development and ripening of sweet orange (Citrus sinensis). BMC Genomics 2012, 13(1):10.

44. Schuster SC: Next-generation sequencing transforms today's biology. Nat Methods 2008, 5:16-18.

45. Shendure J, Ji H: Next-generation DNA sequencing. Nat Biotechnol 2008, 26(10):1135-1145

46. Leida C, Terol J, Marti G, Agusti M, Llacer G, Badenes ML, Rios G: Identification of genes associated with bud dormancy release in Prunus persica by suppression subtractive hybridization. Tree Physiol 2010, 30(5):655-666

47. Kosová K, Vítámvás P, Prášil IT: The role of dehydrins in plant response to cold. Biol Plantarum 2007, 51(4):601-617.

48. Yakovlev I, Asante D, Fossdal C, Partanen J, Junttila O, Johnsen $\varnothing$ : Dehydrins expression related to timing of bud burst in Norway spruce. Planta 2008, 228(3):459-472.

49. Garcia-Bañuelos M, Gardea A, Winzerling J, Vazquez-Moreno L: Characterization of a Midwinter-Expressed Dehydrin (DHN) Gene from Apple Trees (Malus domestica). Plant Mol Biol Rep 2009, 27(4):476-487.

50. Pulla RK, Kim YJ, Kim MK, Senthil KS, In JG, Yang DC: Isolation of a novel dehydrin gene from Codonopsis lanceolata and analysis of its response to abiotic stresses. BMB Rep 2008, 41(4):338-343.

51. Mingeot D, Dauchot N, Van Cutsem P, Watillon B: Characterisation of two cold induced dehydrin genes from Cichorium intybus L. Mol Biol Rep 2009, 36(7):1995-2001

52. Weiss J, Egea-Cortines M: Transcriptomic analysis of cold response in tomato fruits identifies dehydrin as a marker of cold stress. J App/ Genet 2009, 50(4):311-319.

53. Améglio T, Guilliot A, Lacointe A, Julien JL, Alves G, Valentin V, Pétel G: Water relations in winter: effect on bud break of walnut tree. In Dormancy in plants: from whole plant behaviour to cellular control. Edited by Viémont JD, Crabbé J. Wallingford, UK: CAB International; 2000:109-120.

54. Gevaudant F, Petel G, Guilliot A: Differential expression of four members of the $\mathrm{H}^{+}$-ATPase gene family during dormancy of vegetative buds of peach trees. Planta 2001, 212(4):619-626.

55. Horvath DP, Anderson JV, Soto-Suarez M, Chao WS: Transcriptome analysis of leafy spurge (Euphorbia esula) crown buds during shifts in welldefined phases of dormancy. Weed Science 2006, 54(5):821-827.

56. Chang S, Puryear J, Cairney J: A simple and efficient method for isolating RNA from pine trees. Plant Mol Biol Rep 1993, 11(2):113-116.

57. Marioni JC, Mason CE, Mane SM, Stephens M, Gilad Y: RNA-seq: an assessment of technical reproducibility and comparison with gene expression arrays. Genome Res 2008, 18(9):1509-1517.

58. Grabherr MG, Haas BJ, Yassour M, Levin JZ, Thompson DA, Amit I, Adiconis X, Fan L, Raychowdhury R, Zeng QD: Full-length transcriptome assembly from RNA-Seq data without a reference genome. Nat Biotechnol 2011, 29(7):644-652

59. Iseli C, Jongeneel CV, Bucher P: ESTScan: a program for detecting, evaluating, and reconstructing potential coding regions in EST sequences. Proc Int Conf Intell Syst Mol Biol 1999,138-148.

60. Li R, Yu C, Li Y, Lam T-W, Yiu S-M, Kristiansen K, Wang J: SOAP2: an improved ultrafast tool for short read alignment. Bioinformatics 2009, 25(15):1966-1967.

61. Mortazavi A, Williams BA, McCue K, Schaeffer L, Wold B: Mapping and quantifying mammalian transcriptomes by RNA-Seq. Nat Methods 2008, 5(7):621-628.

62. Audic S, Claverie JM: The significance of digital gene expression profiles Genome Res 1997, 7(10):986-995.

63. Benjamini $Y$, Hochberg $Y$ : Controlling the false discovery rate: a practical and powerful approach to multiple testing. Journal of the Royal Statistical Society Series B-Methodological 1995, 57(1):289-300.

64. de Hoon MJL, Imoto S, Nolan J, Miyano S: Open source clustering software. Bioinformatics 2004, 20(9):1453-1454. 
65. Saldanha AJ: Java Treeview—extensible visualization of microarray data. Bioinformatics 2004, 20(17):3246-3248.

66. Tamura K, Dudley J, Nei M, Kumar S: MEGA4: molecular evolutionary genetics analysis (MEGA) software version 4.0. Mol Biol Evol 2007. 24(8):1596-1599.

67. Zhang D, Yu B, Bai J, Qian M, Shu Q, Su J, Teng Y: Effects of high temperatures on UV-B/visible irradiation induced postharvest anthocyanin accumulation in 'Yunhongli No. 1' (Pyrus pyrifolia Nakai) pears. Sci Hortic 2012, 134:53-59.

doi:10.1186/1471-2164-13-700

Cite this article as: Liu et al.: Transcriptomic analysis of 'Suli' pear (Pyrus pyrifolia white pear group) buds during the dormancy by RNA-Seq. BMC Genomics 2012 13:700.

\section{Submit your next manuscript to BioMed Central and take full advantage of:}

- Convenient online submission

- Thorough peer review

- No space constraints or color figure charges

- Immediate publication on acceptance

- Inclusion in PubMed, CAS, Scopus and Google Scholar

- Research which is freely available for redistribution 